Dieses Dokument ist eine Zweitveröffentlichung (Verlagsversion) / This is a self-archiving document (published version):

Pierre Karrasch, Christine Wessollek

Evaluation of MODIS NDVI based phenology indicators for the analysis of vegetation dynamics in the nature reserve Königsbrücker Heide

Erstveröffentlichung in / First published in:

SPIE Remote Sensing. Berlin, 2018. Bellingham: SPIE, Vol. 10790 [Zugriff am: 02.05.2019].

DOI: https://doi.org/10.1117/12.2325549

Diese Version ist verfügbar / This version is available on:

https://nbn-resolving.org/urn:nbn:de:bsz:14-qucosa2-351792

„Dieser Beitrag ist mit Zustimmung des Rechteinhabers aufgrund einer (DFGgeförderten) Allianz- bzw. Nationallizenz frei zugänglich."

This publication is openly accessible with the permission of the copyright owner. The permission is granted within a nationwide license, supported by the German Research Foundation (abbr. in German DFG).

www.nationallizenzen.de/ 


\section{Evaluation of MODIS NDVI based phenology indicators for the analysis of vegetation dynamics in the nature reserve Königsbrücker Heide}

Pierre Karrasch, Christine Wessollek

Pierre Karrasch, Christine Wessollek, "Evaluation of MODIS NDVI based phenology indicators for the analysis of vegetation dynamics in the nature reserve Königsbrücker Heide," Proc. SPIE 10790, Earth Resources and Environmental Remote Sensing/GIS Applications IX, 107900Y (9 October 2018); doi: 10.1117/12.2325549

SPIE. Event: SPIE Remote Sensing, 2018, Berlin, Germany 


\title{
Evaluation of MODIS NDVI based phenology indicators for the analysis of vegetation dynamics in the nature reserve Königsbrücker Heide
}

\author{
Pierre Karrasch $^{a}$ and Christine Wessollek $^{b}$ \\ ${ }^{a}$ Chair of Geoinformatics, Technische Universität Dresden, Helmholtzstraße 10, 01069 Dresden, \\ Germany ${ }^{b}$ Technische Universität Dresden, Helmholtzstraße 10, 01069 Dresden, Germany
}

\begin{abstract}
The analyses of trends in vegetation dynamics require a profound knowledge of its seasonality. For the determination of the seasonality conventional methods of time series analyses often use a simple averaging of measured values of the identical time in different cycle of the whole time series (e.g. bfast). Then it is assumed that the resulting seasonal portion of a time series is constant and stable for the entire time series. However, analyses of vegetation time series show that trends in vegetation dynamics do not always run steadily, but show structural breaks, especially in regions with high potential for possible landscape changes. For such conversion areas, the assumption of a constant seasonality is not always ensured. The dynamic or variability of the seasonality can have temporal effects by a shift of the start of the season (SOS) or the end of the season (EOS) and therefore also on the length of the vegetation period. To show whether seasonal dynamics can be detected in vegetation time series, two requirements must be fulfilled. (1) High-temporal resolution vegetation information provided for example as MODIS-NDVI. (2) Indicators are needed which allows the description of the variability of seasonality. As a result these metrics allow a better modeling of long-term vegetation dynamics in the trend, taking into account the variability of the seasonality. But at the same time the metrics itself serve as indicators for long term vegetation dynamics. The aim of the present study is to analyse phenological and greenness metrics for the modelling of vegetation dynamics in the nature reserve Königsbrücker Heide. Detailed analyses of key metrics like SOS and EOS using different metric approaches and interpolation methods are applied and compared. The results show that it is difficult to determine consistent information for example for the trend of single phenology metrics.
\end{abstract}

Keywords: vegetation dynamics, MODIS NDVI, seasonality, phenology metrics, nature protection

\section{INTRODUCTION \& MOTIVATION}

The International Union for Conservation of Nature and Natural Resources (IUCN) defined protected area as "a clearly defined geographical space, recognized, dedicated and managed, through legal or other effective means, to achieve the long term conservation of nature with associated ecosystem services and cultural values." ${ }^{1}$ In the Federal Republic of Germany, according to the Federal Agency for Nature Conservation (BfN), the monitoring of protected areas (national parks, biosphere reserves, nature parks) is an integral part of resource management. In addition to insitu-observations, methods of remote sensing gained in importance. The extent and limited accessibility of protected areas, depending of the protection status, arise the need for measurements without direct interaction with study area. In these cases, the use of remote sensing methodology and data can make a valuable contribution. ${ }^{1,2}$ For protected areas Nagendra (2013) provide a survey of the use of various remote sensing systems for different monitoring tasks. ${ }^{3}$ Especially in areas with a high pressure on landscape, dense time series can meaningfully support monitoring if these time series cover at least a period of 10 years. ${ }^{4}$ The products of the sensor MODIS are highly recommended as they provide a number of products for the description of phenology. ${ }^{5}$ The Normalized Difference Vegetation Index (NDVI) is an important parameter for evaluating vegetation status over time. ${ }^{6}$ Therefore NDVI times series of different remote sensing systems are available

Further author information: (Send correspondence to Christine Wessollek.) Christine Wessollek: E-mail: christine.wessollek@tu-dresden.de

Earth Resources and Environmental Remote Sensing/GIS Applications IX, edited by Ulrich Michel,

Karsten Schulz, Proc. of SPIE Vol. 10790, 107900Y · (c) 2018 SPIE

CCC code: $0277-786 \mathrm{X} / 18 / \$ 18 \cdot$ doi: $10.1117 / 12.2325549$

Proc. of SPIE Vol. $10790107900 Y-1$ 
in different temporal and spatial resolutions (e.g. Terra MODIS NDVI, AVHRR GIMMS, SPOT VGT). They were used in numerous studies of vegetation monitoring in various vegetation zones and different scales ranging from global to local, showing the contribution using remote sensing data in conjunction with methods of applied spatial data analysis for monitoring programs in protected areas. ${ }^{7-16}$ Wessels et al. (2012) used AVHRR data to investigate trend analysis methods applied to remotely sensed vegetation index data for the detection of land degradation and simulated land degradation in the Kruger National Park. ${ }^{7}$ AVHRR NDVI data were also used by Weiss et al. (2001) to perform a linear regression of vegetative biomass change in Saudi Arabia's rangelands to evaluate the effects of grazing by the animal herds of indigenous nomads. ${ }^{15}$ De Beurs and Henebry (2005) used AVHRR data to analyse to which extent the institutional changes accompanying the collapse of the Soviet Union resulted in significant changes in land surface phenologies across the ecoregions of Kazakhstan. ${ }^{14}$ An investigation on greening and browning trends was done by de Jong et al. (2011) based on on phenological measures derived from AVHRR GIMMS. A comparison of different time series datasets (AVHRR GIMMS, Terra MODIS, SPOT VGT) was performed by Fensholt et al. (2009) by a time series trend analysis in the Sahel and Sudanian zones in Africa.

Also the usefulness of the MODIS NDVI data, used in the present study, was proven in several studies with different focus. For example, the damages on forests due to the 2003 summer heat wave, characterized by very high temperatures associated with drought, were analysed by Lambert et al. (2003) for two selected provinces located in the South-West of France, where a large percentage of wooded areas were impacted. ${ }^{8}$ Another study in Europe was done by Karlsen et al. (2008). They used MODIS NDVI data for the mapping of the length of the growing season in northern Fennoscandia and compared this satellite derived results with ground-based phenology data on birchs, which were used to derive phenophases. ${ }^{9}$ A trend analysis to quantify vegetation cover degradation in the north-west of Madagascar based on MODIS NDVI times series was performed by Jacquin et al. $(2010)^{10}$ whereas Hutchinson et al. (2015) aims to to support sustainable management of military training land by analysing MODIS NDVI data for the identification of vegetation-related environmental impacts caused by training activities. ${ }^{11}$ In particular, the temporal resolution of the data is crucial in determining whether short-term phenological processes can be described with sufficient accuracy. ${ }^{9,13,17}$

Protected areas such as the Königsbrücker Heide are particularly suitable for methods of time series analysis based on remote-sensing data in order to answer methodological as well as conservation-related questions. At the beginning of the 1990s, the Königsbrücker Heide was one of many military training areas of the former GDR. Until 1989, up to 1.5 million soldiers were stationed in the territory of the GDR. With the political changes, many of these areas were no longer needed for military use. Since 1996 the Königsbrücker Heide is declared as the nature reserve (NSG) and is, with an area of approximately $69.3 \mathrm{~km}^{2}$, one of the largest unfragmented nature reserves in Germany. The fact that large areas are restricted due to the still existing military equipment and weaponry remains enables the opportunity that one of the largest non-fragmented landscapes can develop mostly without human activities. Today the Königsbrücker Heide is subdivided into three zones. In the natural development zone, natural processes can take place without human influence. In the zone of controlled succession, where mainly all the military activities took place, open land habitat dominate. These open land habitats are preserved by selective intervention, which means that succession processes are actively disturbed. The buffer zone essentially serves to delimit the surrounding cultural landscape and is characterized by pine forests (see figure 1 , left). ${ }^{18}$

Various remote-sensing investigations in recent years have shown that, after the leaving of the Soviet Forces, strong vegetation dynamics has taken place. Wessollek and Karrasch (2016) showed that there were significant increases in the vegetation signal (MODIS NDVI) in large parts of the protected area. ${ }^{19}$ It also became clear that this dynamics of the trend did not occur steadily, but was disturbed by structural breaks of varying intensity. The causes of these structural breaks have natural character, due to anomalies in climatic conditions like temperature and precipitation or else are related to management activities of the protected area administration. ${ }^{20}$ The previous time series analysis and breakpoint detection in this study area assumed a constant seasonality over the whole observation period $(2000$ - 2016). The results, however, suggest that this assumption may not be applicable. For this reason, the following investigations should extend the analyses of the previous vegetation dynamics. Phenological and Greeness Metrics (PGM) offer the opportunity to observe certain phases of vegetation development during the year. These include, for example, the start of the vegetation season (SOS) 
or the end of the vegetation season (EOS). These metrics are calculated for each year and therefore also constitute timeseries that may be subject to dynamics or trends. Timeseries analyses of the derived metrics can provide information about changes in the vegetation period, e.g. length of the growing season. ${ }^{9,17,21-23}$

In this context, it will be investigated for the Königsbrücker Heide whether changes in the vegetation period occur during the observation period. The analyses focus on the start (SOS), the end (EOS) and the length of the season (LOS). Since different approaches for the calculation of the PGM are available and also different methods of interpolation of the underlying time series can be used, it will also be examined how the results differ with regard to the method used.

\section{METHODS \& MATERIALS}

The following analyses are based on NDVI data products of the MODIS sensor which is available on both the Terra and the Aqua satellite and provides NDVI time series since the year 2000. The data have a geometrical resolution of $250 \mathrm{~m}$ and are available every 16 days. ${ }^{24,25}$ As part of the preprocessing of the data, the NDVI values were stretched to a range of $+/-10,000$. The analysis for the completeness of the data shows, that in the period from 2000 to 2015 there are gaps in some places of the study area. Figure 1 shows that in the analysed 16 years of study, not all 367 observations per pixel did contain valid data. In maximum 7 observations were missing in a single time series, but these gaps never occurred in a row.
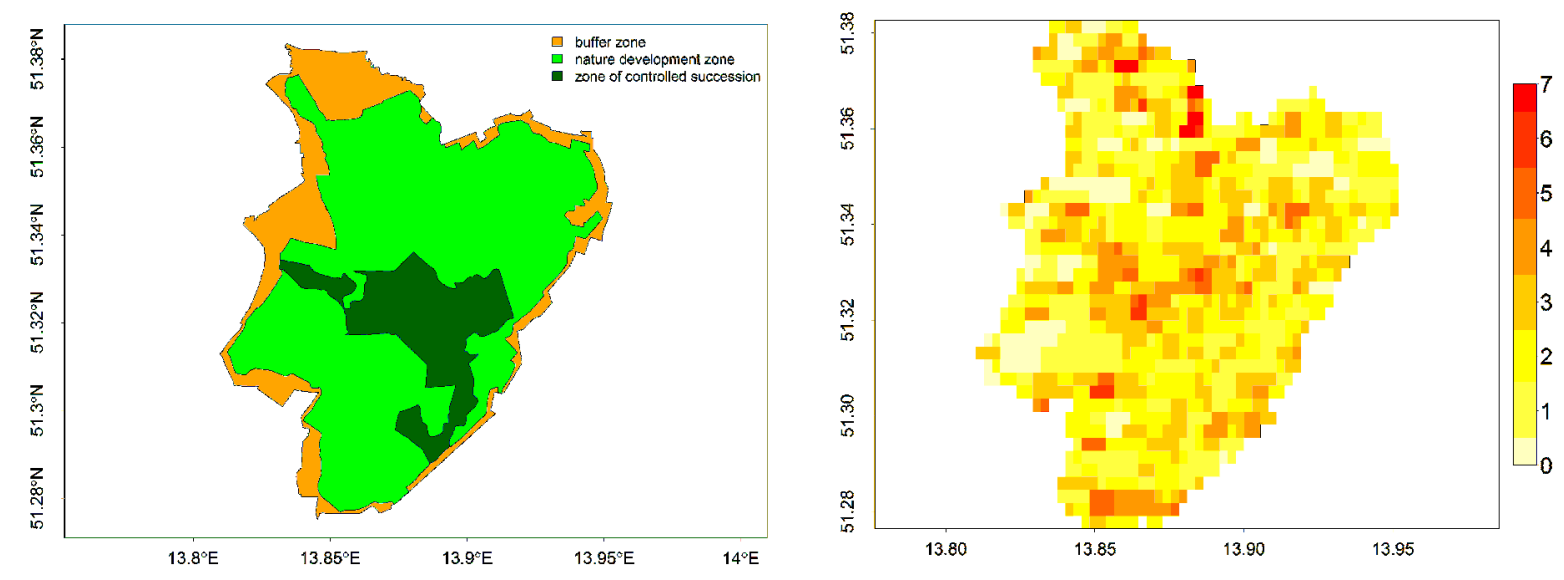

Figure 1. left: Protection zones of the nature reserve "Königsbrücker Heide"; right: Spatial distribution and absolute frequency of data gaps (15 years, 367 observations)

The reasons for missing data are manifold. This includes, for example, the presence of snow in the winter months. Since the chosen methodology requires complete and gapless data sets, interpolation of these data gaps is necessary in a first preprocessing step. There are a several methods and algorithms available. ${ }^{26-29}$ A good overview gives Kandasamy (2013). ${ }^{30}$ In the present case it was decided to interpolate the few gaps using a Kalman filter. ${ }^{31-33}$ Finally, for the entire area of the Königsbrücker Heide, there are 1,203 time series with a length of 367 observations available for further processing.

The temporal resolution of the used data is not sufficient to determine the below explained phenology metrics with sufficient accuracy. For this reason, it is necessary to perform a temporal interpolation of all individual time series to a daily resolution. There are several methods available that have been used as part of the greenbrownpackages by Forkel et al. (2015). ${ }^{17}$ The Singular Spectrum Analysis - SSA fills in missing values using a 1dimensional spectrum analysis and also uses this technique to smooth the curve. ${ }^{34,35}$ The linear interpolation is done using a linear approach and is completed by using a running median. ${ }^{36}$ The spline interpolation is based on filling in the missing time values with the help of a cubic spline interpolation, which is then smoothed. ${ }^{37-39}$ The STM-interpolation method fills the gaps in the time series with the help of the season-trend-model of Verbesselt $(2010,2012){ }^{40,41}$ Based on these methods, the interpolation results are compared in the form of correlation analyses and by their differences. 
The used phenology and greenness metrics (PGMs) implemented in the greenbrown-package are based on the calculation of two key points on the smoothed seasonality curve. On the one hand, this is the start of the growing season (SOS) and the end of the growing season (EOS). There are different approaches for determining these two specific times. Clerici et al. (2012) introduced an approach that uses different forms of one-sided averaging of the smoothed curve which leads to a virtual shift of that curve. The intersection of this averaged curve and the original curve are the SOS and EOS points. ${ }^{42}$ But that key points are very low on the seasonality curve. However, Forkel et al. 2015 concludes that these values are strongly influenced by non-vegetation changes (e.g. snow cover, cloud contaminations). ${ }^{17}$ Because these points are not very reliable other approaches are preferred that define the SOS and EOS as the mid-points of spring greenup and autumn senescence, respectively. Therefore the first two approaches use thresholds to derive the SOS and EOS. While for the TRS approach a simple threshold based on the amplitude of the series is used, the White approach uses the $50 \%$ level of the greenness curve in spring and in autumn for the determination of the SOS and EOS. ${ }^{43}$ The third, the Deriv approach, uses the derivative of the seasonal curve to extract the key metrics SOS and EOS. ${ }^{21}$

All further PGMs are derived from the key metrics SOS and EOS. ${ }^{17}$ This includes in particular the length of season (LOS), which is the difference between EOS and SOS. The mean growing season (MGS) is the mean value between the SOS and EOS. Further the mean spring (MSP) and mean autumn (MAU) values are calculated by averaging the NDVI values +/- 10 days around the SOS and EOS. The Position of Peak (POP) and the peak value (PEAK) of the smoothed curve are two indicators for the time and level of photosynthetic activity. The counterpart of these metrics is the position of through (POT) and the value of through (THROUGH). These metrics are calculated for the entire research area of the Königsbrücker Heide and are available for further evaluation. This is done for individual areas in the different protection zones and for the entire protected area. All derived metrics are time series that form the basis for a simple area-wide regression analysis. Basic statistical methods should then provide information on whether there are significant changes in the seasonal vegetation dynamics. As described above, the influence of the selected interpolation method is described.

\section{RESULTS}

\subsection{Analysing the interpolation methods}

As explained in the chapter Methods $\&$ Materials, various interpolation methods are available to interpolate the existing signal with 23 NDVI values per year into a daily signal. Due to the fact that there is no data to validate the quality of the interpolation methods, they should be compared with each other. In a first step, the correlations are calculated in pairs between the interpolated time series. For the entire study period, these correlations range from 0.76 to 0.97 (see Figure 2, left) for a selected time series in the nature development zone of the study area. However, the different plots also show that there are a number of outliers whose course is partly opposite to the main correlation direction. This suggests, that there may be large local differences in the course of the resulting interpolations (see Figure 2, right).

This impression is confirmed by the differences shown in Figure 2 (right). For the same time series, it can be seen that the differences between the NDVI values interpolated to a daily resolution can range from -4000 to +3000 depending on the methods uses for comparison. If such values will be used in determining the key metrics SOS and EOS, they would affect all other phenological metrics based on these values. As an example, Figure 3 (below) shows the results of the interpolations for the period 2000-2003 for a selected time series in the nature development zone. The illustrated curves show that in particular the linear interpolation (orange) closely follows the original values of the NDVI time series. Which leads to the assumptions that the smoothed and interpolated time series might still contain to much interannual variability. The influence of individual points on the determination of a seasonal signal is clearly visible. In contrast, the results of the STM interpolation (blue) show a high degree of homogeneity over time, which cannot adequately reflect the changes in the NDVI over the years. Only the results of the spline interpolation and SSA interpolation seem to follow the course of the NDVI signal adequately.

Also, the results of the correlations between these interpolations as well as the evaluation of the differences of the signals leads to the decision to exclude the results of the linar interpolation and the STM interpolation from the further analysis. For the calculation of the phenology metrics only the spline interpolation as well as the SSA interpolation were taken into account. 

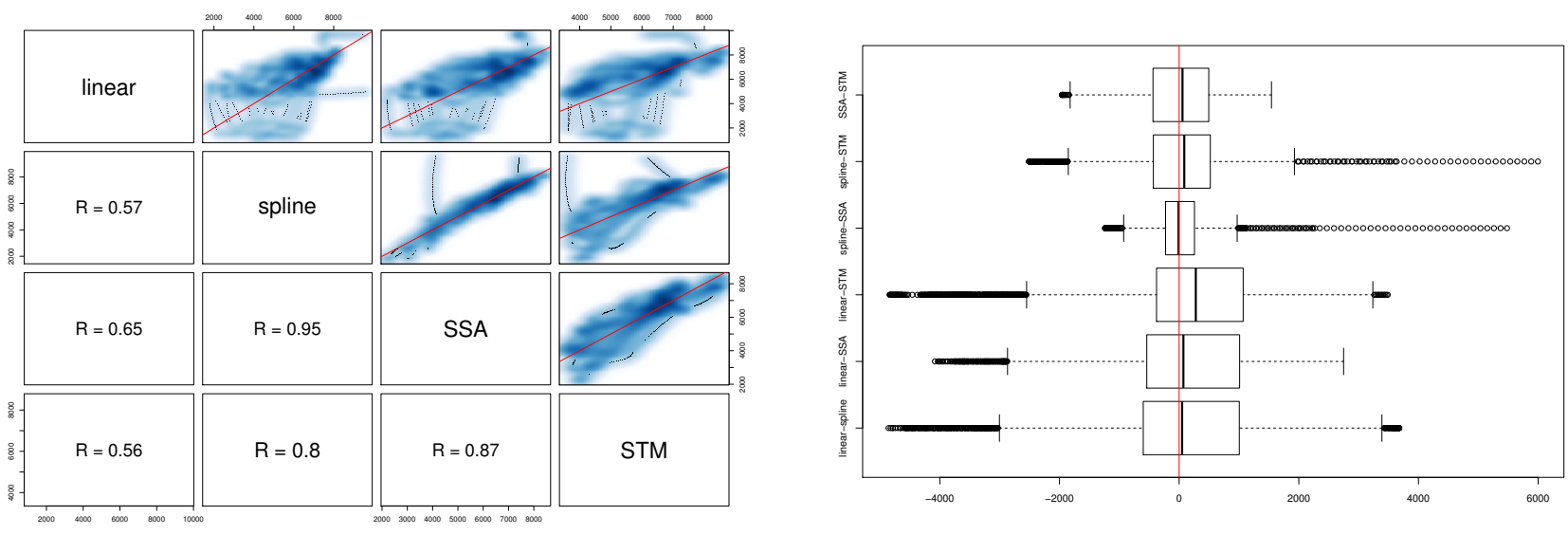

Figure 2. Left: Pairwise scatterplots and correlations between different interpolation methods for a selected NDVI time series in the study area; Right: Distribution of pairwise differences of different interpolation methods for a selected NDVI time series in the study area.

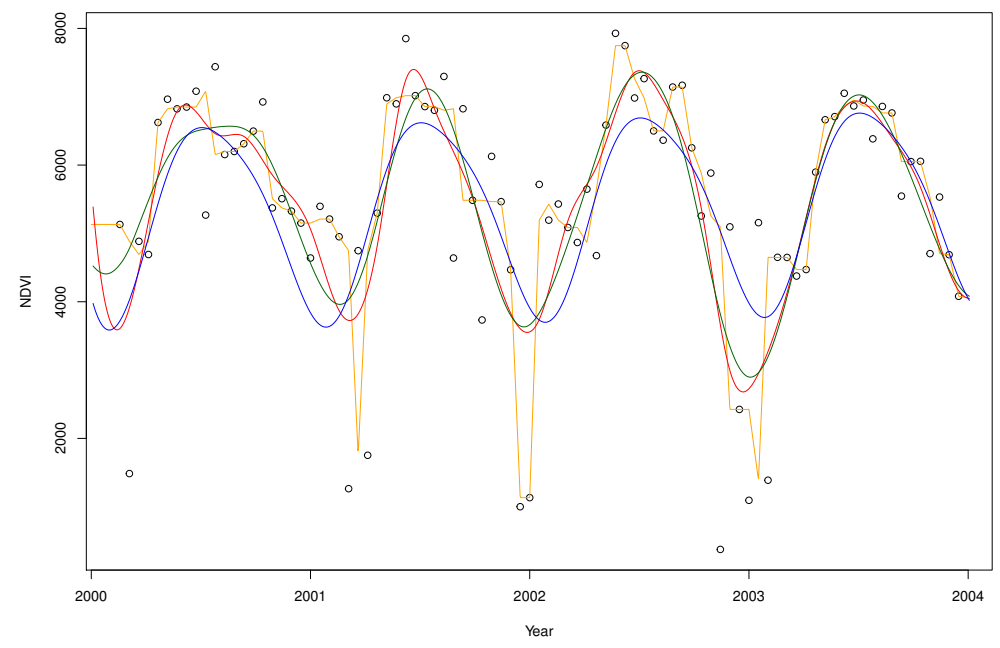

Figure 3. Results of different interpolation methods for a section of four years (orange: linear, blue: STM, red: spline, green: SSA)

\subsection{Phenological and Greenness Metrics}

Based on the findings of the previous analyses of the interpolation methods, the spline interpolation as well as the SSA interpolation are investigated regarding their impact on the calculation of the metrics. Since different approaches can also be used for the calculation of the metrics (see chapter Methods $\& 5$ Materials), the key metrics for calculating the SOS and EOS are carried out for both interpolation methods (spline, SSA) combined with all three calculation approaches (Deriv, TRS, White). With this procedure each phenology metric was calculated in six combinations to asses the influence of the choice of interpolation method and approach to derive the phenology metrics. To get an idea of the similarities and differences between this six variations, scatterplots for each metric were created. From Figure 4, showing examplary the results for the SOS over the entire study area as well as for 16 years, some significant differences are apparent.

Figure 5 shows an example of the deviations for two selected combinations of interpolation method and approaches of metric determination. In the figure on the left, the results of the spline and SSA interpolation 


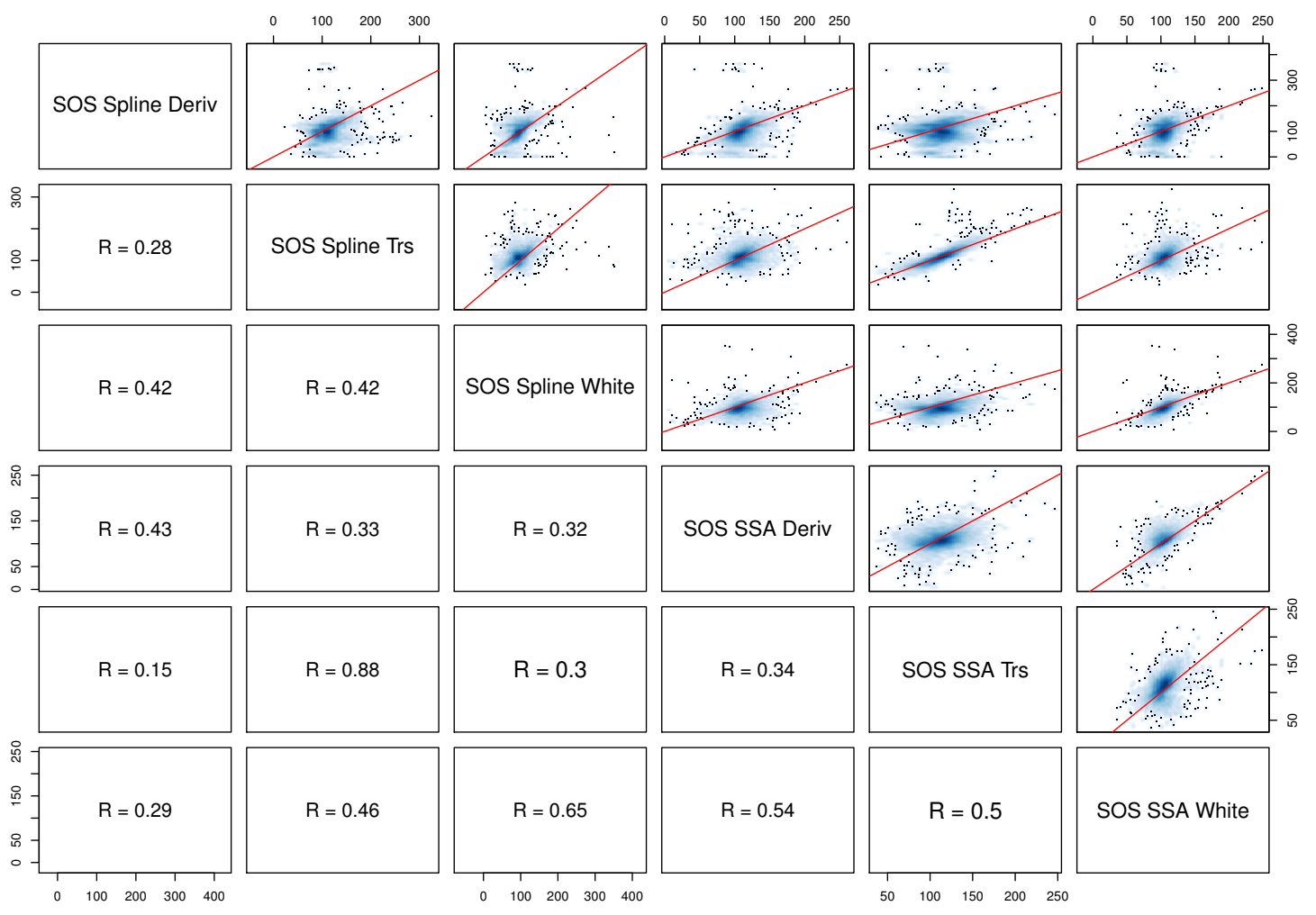

Figure 4. Pairwise scatterplots and correlations for SOS between different interpolation methods and phenology metric approaches)

are compared for the TRS approach. It becomes clear that there are differences in the SOS, but that both analyses provide primarily comparable results. Otherwise, the figure on the right shows that when comparing two SOS calculations for spline-interpolated NDVI time series with different metric approaches (Deriv-TRS), the deviations are significantly higher.

These analyses can also be performed for the second key metric End of Season (EOS). The results are quite comparable. In summary, it can be stated that the combination of interpolation methods and phenology metric approach can have a significant influence on the calculation of the key metrics SOS and EOS.

Because it is difficult to visualize the areal and temporal development of the metrics, the start of season (SOS) for each year was plotted for the whole area as box plots. The results are shown in Figure 6.

On the one hand the results show that despite the relatively small study area of the Königsbrücker Heide, the variability or scattering of the SOS values is very high, independent of the used methods (interpolation, metric). Also, no general trend of the metrics can be documented from these results. This applies for the SOS and also for the other metrics presented in the method chapter. The results suggest that due to the high variability of the metrics in the whole area, it may be more useful to analysis the development of the metrics over time. For this purpose, time series of all metrics were calculated for each pixel and put into a simple regression analysis. Figure 7 shows the results for the metrics SOS, EOS and LOS for a selected location in the nature development zone.

The two presented results are exemplary for the entire study area (1203 time series) and the six calculations resulting from the interpolation methods and the metric approaches. At the same time, a complete computation of all metrics, as described in the chapter Methods 85 Materials is applied. In the specific case, the two examples show that there is a shift, especially for the End of Season (EOS). Due to a largely constant Start of Season 

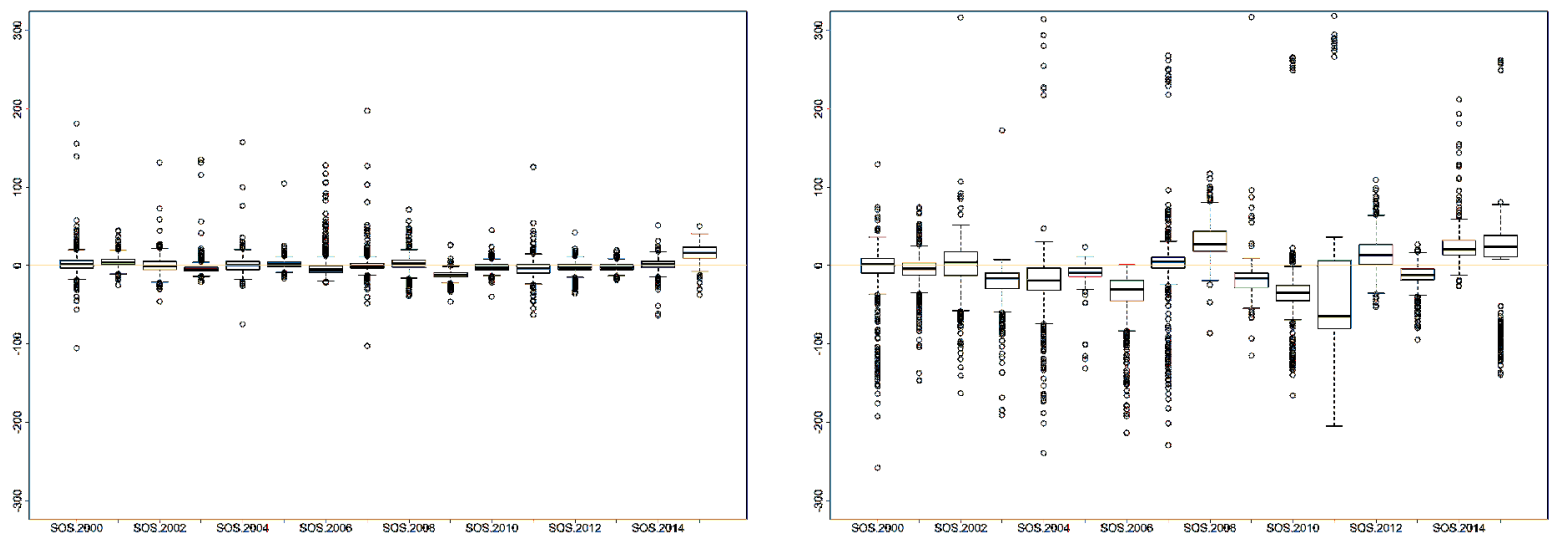

Figure 5. Differences of Calculation the Start of Season (SOS); Left: Spline-SSA (TRS approach); Right: Deriv-TRS (Spline interpolation)
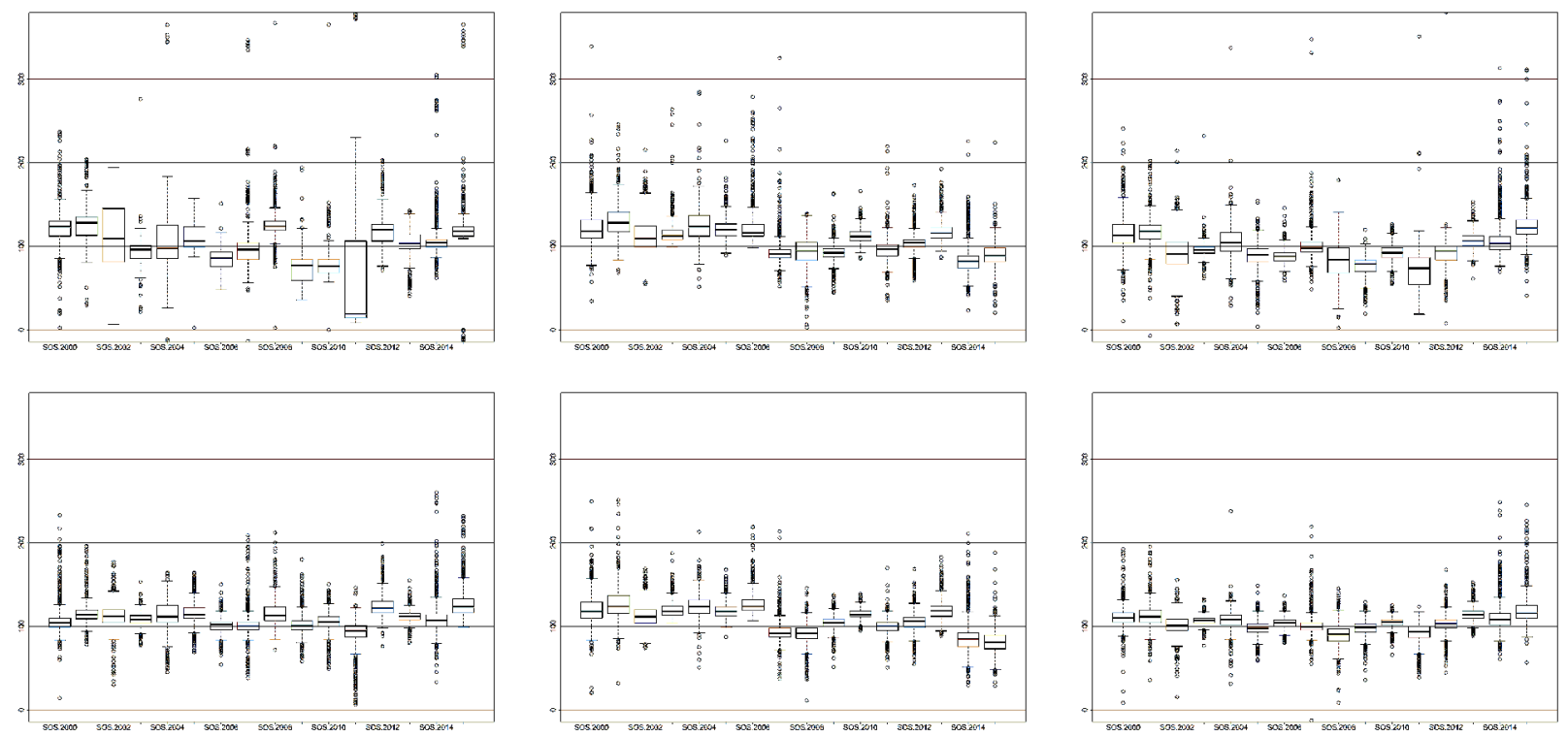

Figure 6. Start of Season in the Königsbrücker Heide for different interpolation methods and metric approaches; 1st row: spline interpolation (Deriv/TRS/White); 2nd row: SSA interpolation (Deriv/TRS/White)

(SOS), however, there is an overall increase in the length of the vegetation season (LOS). But it must be noted that such clear results are not in every place and are very variable regarding the six combination of interpolation methods and metric approaches, therefore a clear statements for the entire the study area cannot be made on the basis of these two examples.

Nevertheless, the results of the development of the metrics should be presented in the following figures. As can be seen from the results for the SOS shown in Table 1, the results depend on the combination of interpolation method and phenology metric approach. Thus, spatially different directions of developments can be determined. For the SSA interpolated NDVI values mainly positive developments can be identified for the approach White and Deriv. That corresponds with a postponement of the SOS to a later date in the year. In contrast,the results of the TRS approach show the opposite trend. Here mostly negative developments are visible, i.e. shifts to an earlier point in the year. In principle, these results can also be found for the spline-interpolated values. Especially in the zone of controlled succession, the positive increases of the SOS time series are less pronounced. For the 

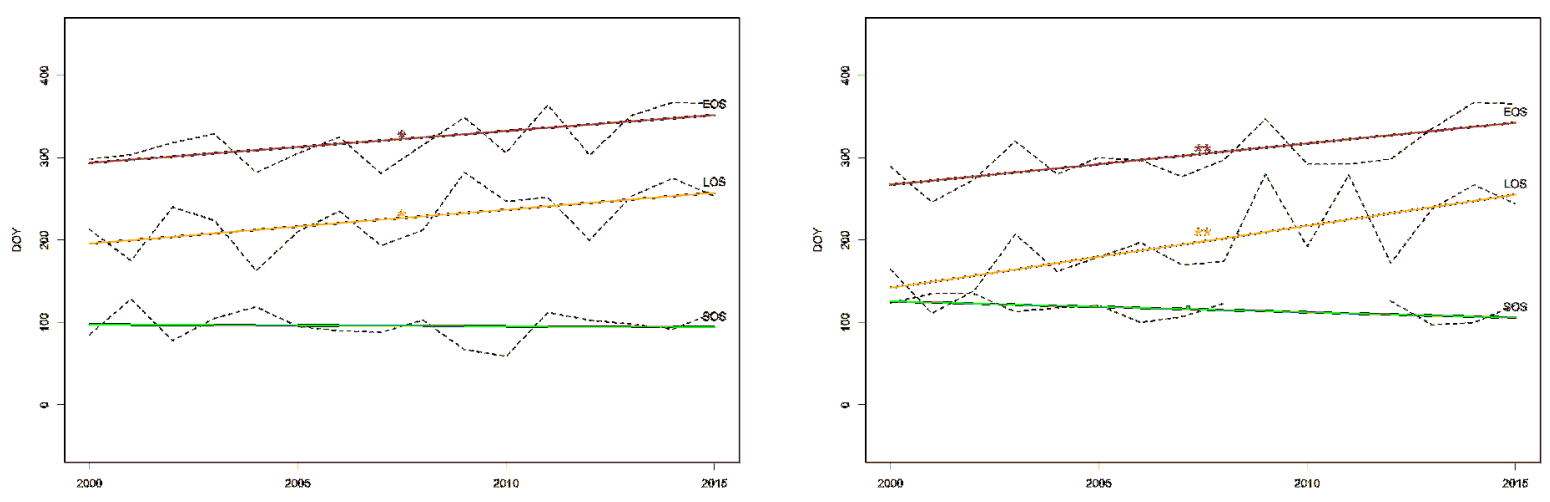

Figure 7. Two examples of SOS, EOS and LOS calculation for two selected locations in the nature developement zone (spline interpolation, Deriv approach)

approach Deriv, the direction of the trend even reverses. Overall, it can be stated that no clear statements can be made regarding a trend in the SOS.

The assessment of validity of the determined vegetation dynamics is done with the help of the corresponding p-values of the trend calculation. Again, it becomes clear that the results are very different. Thus, for the $S S A$ interpolation and the metric approaches White and Deriv, in some cases very high p-values can be detected in the study area, which indicates that no linear trend occurs. The p-values of the TRS approach indicate another result. Here it can be seen, that for a large part of the study area trends in the Start of Season can be determined (SSA: $43.9 \%$, spline: $50.6 \%$ ). The same is true for the results based on spline interpolation. Here, it can be seen that the p-values of the White and the Deriv approach are partly very high compared to the SSA interpolation, but especially in the zone of controlled succession they are significantly lower. For the TRS approach it can be stated, that hardly any differences between the results of the two applied interpolation methods are apparent.

Considering the results of the second key metric (End of Season), almost completely positive trends can be found in the study area, especially for the slopes in SSA interpolation. On the other hand, for the spline interpolation, some parts of the Königsbrücker Heide show negative slope values. Here, an area in the north (zone of controlled succession) is striking. Assessing the p-values of the linear regression, it can be stated that, in comparison with the results of the analyses of the Start of Season, the TRS approach has very low p-values. For the other two approaches, the p-values are significantly above 0.1 for large areas. While for the TRS approach on the spline-interpolated data nearly $57 \%$ of p-values are below the limit of 0.05 . For the other two metric approaches on both interpolation methods the number of p-values below 0.05 ranges only from $6.1 \%$ to $15.7 \%$ (cf. Table 2).

Both, the differences between the individual annual calculations of the key metrics and the temporal evaluation of the dynamics of these metrics show that no reliable statements regarding the key metrics can currently be made. Due to the fact that the calculations of additional metrics are based on these two key metrics, it must be assumed that these uncertainties are also transferred to these metrics. Nevertheless, based on the previous findings, two results for the Length of Season (LOS) will be shown as an example for derived metrics. Table 3 shows the slopes of a linear regressions for spline interpolated NDVI-values using the Deriv and TRS approach. It becomes clear that the TRS approach results in much higher slopes for the same phenomenon. However, the associated p-values indicate that the results are also differentially reliable.

Apart from the p-values also the range of the slopes indicate to deal critically with the results. The plausibility of the slopes, especially in the zone of controlled succession in the north, seems questionable. The example depicted in Figure 8 shows a significant trend for the Start of Season as well as for the End of Season. The shift of the Start of Season to an earlier date in the year, with simultaneous shift of the End of Season to a later date in the year, significantly extend the length of season from about 100 days in 2000 to almost 300 days in 2015 . 
Table 1. Slope of the linear regression of SOS for different metric approaches and interpolation methods (2000-2015)

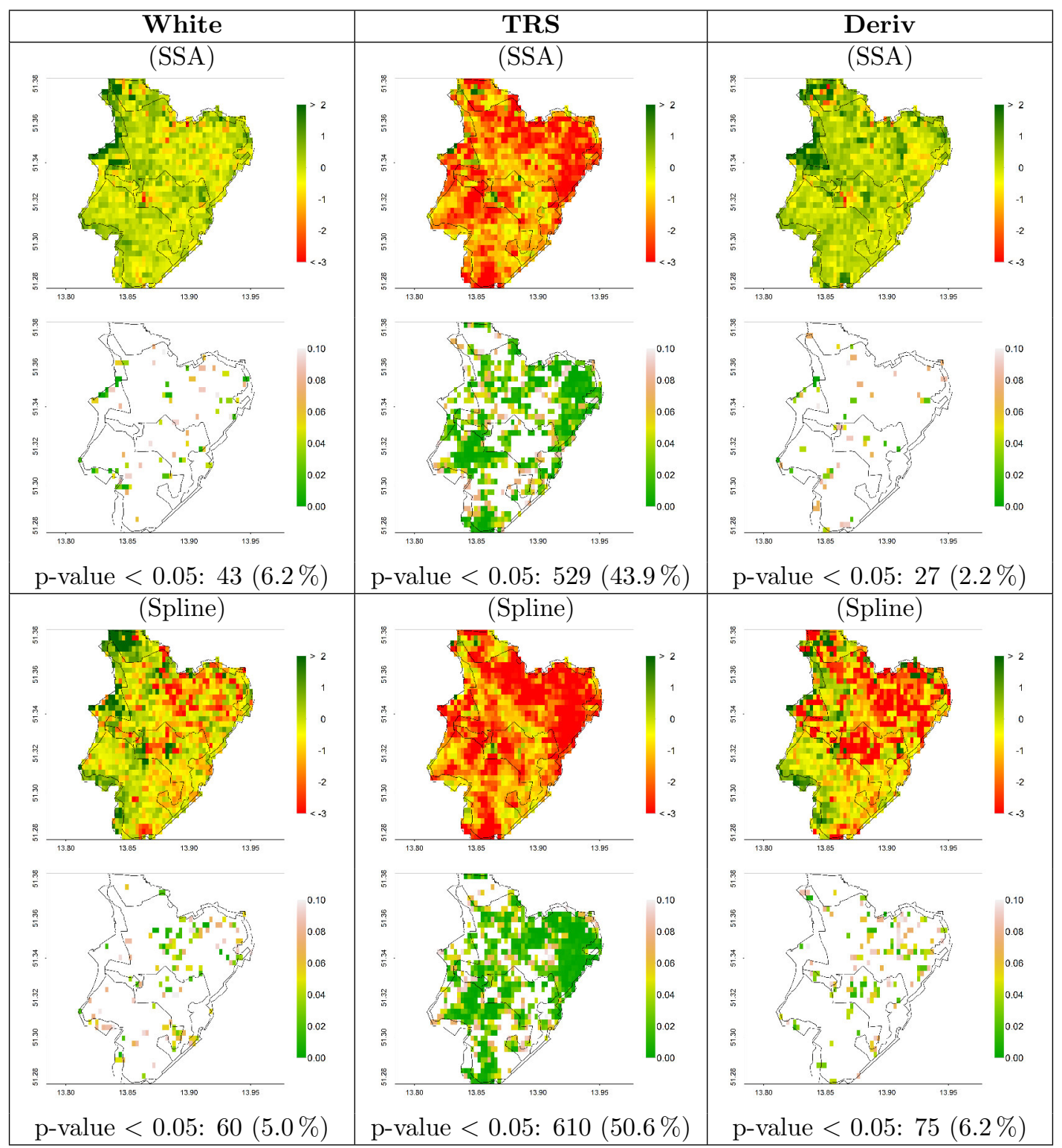

The question to what extent such a trend is actually due to a shift in the key metrics or is caused e.g. by changes in the land cover remains open at this point.

Since the results of the quantitative modeling of the vegetation dynamic based on linear regression shows high variability across the combination of interpolation methods and PGM approaches, a Mann-Kendall test on trends is performed in order to obtain statements whether a fundamental trend can be recognized in the metrics, especially in the Length of Season. But also for this non-parametric test the results reveal difference between the different methods and approaches. Again, the TRS approach confirms the presence of a trend. In particular, as already mentioned in the zone of controlled succession in the north of the Königsbrücker Heide, this approach indicates a negative trend for the SOS, i.e. an earlier start of the vegetation period. For the EOS, the results in this area are clearly more heterogeneous and show on a high significance level both, negative and positive, trends. These results also affect the length of the growing season (cf. Table 4). Again, it can be seen 
Table 2. Slope of the linear regression of EOS for different metric approaches and interpolation methods (2000-2015)

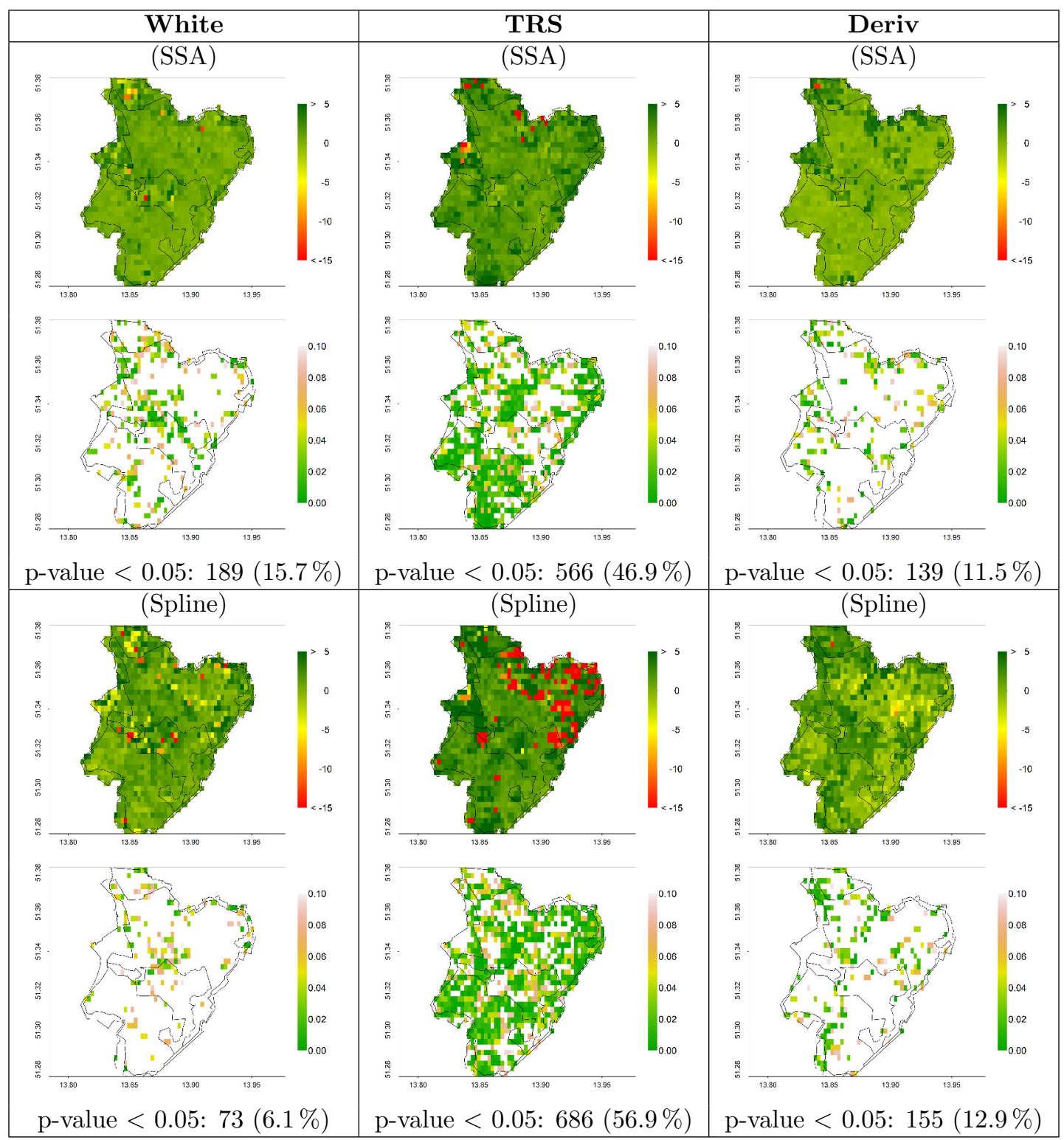

that the approaches White and Deriv differ significantly from the TRS approach. The strength of the trend is significantly higher with the TRS approach with $77.9 \%$ respectively $80.7 \%$ of the associated p-value below 0.05 .

In summary, it can be stated that the sensitivity of the results is very high regarding the methodologies for calculating the metrics. Under the given circumstances, it is currently not possible to derive a clear statement regarding trends in vegetation dynamics.

\section{DISCUSSION \& CONCLUSION}

Based on the results presented, it is necessary to have a discussion on different levels. So initially the used data have to be discussed. The geometric resolution of the data is relatively coarse with $250 \mathrm{~m}$ compared to other optical remote sensing systems. In connection with the heterogeneity of the study area, it cannot always be assumed that similar vegetation within each pixel is responsible for the genesis of the respective NDVI value. 
Table 3. Slope of the linear regression of LOS for selected metric approaches and spline interpolation (2000-2015)

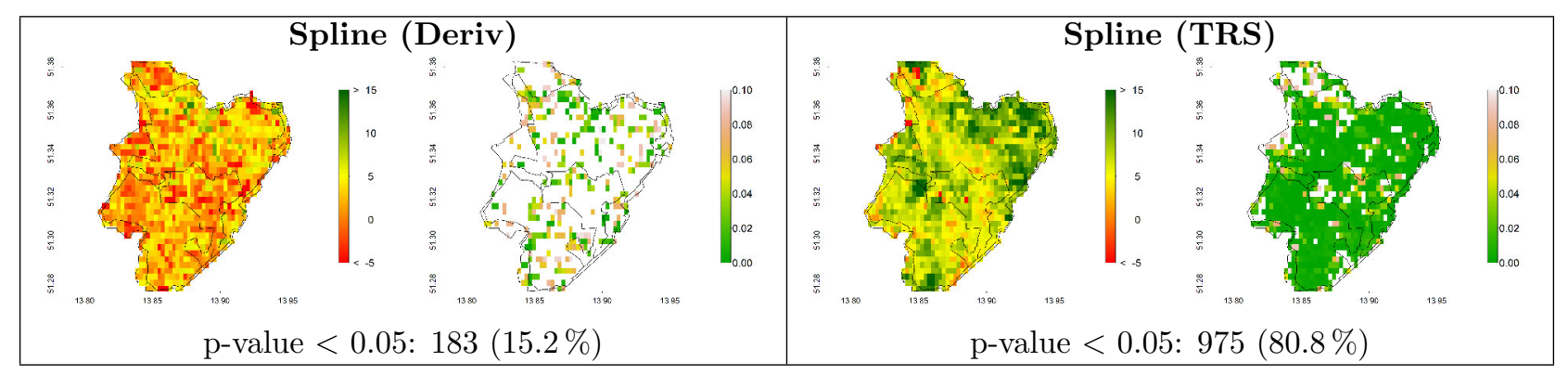

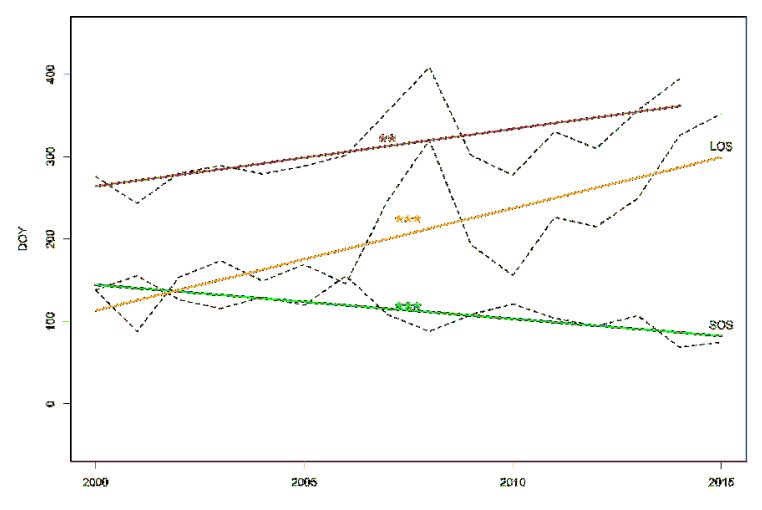

Figure 8. Example of high increase of LOS during the observation period

Especially in the areas in which the former military area of an open landscape has been transformed into a heath. Figure 9 shows that, especially in the zone of the controlled succession in the north of the study area, vegetation has developed in the first place. Although it can be seen that there are already significant changes between the last military use of the Königsbrücker Heide in 1992 and the beginning of the used MODIS time series in 2000, it can also be seen that, there have been fundamental changes in land cover after 2000. Since these do not occur uniformly in the study area, the existing geometric resolution of $250 \mathrm{~m}$ can lead to effects in the vegetation dynamics not being fully reflected in the NDVI data.

At the same time, the three satellite images in figure 9 also show that the present time series, which only takes into account the years 2000 to 2015 , is too short to show corresponding vegetation dynamics. For example, time series could be used that can provide information about the NDVI since the early 1990s. However, such GIMMS data only have a temporal resolution of 30 days and, moreover, a geometric resolution of only $8 \mathrm{~km}$, which would even increase the problem described above. Under these circumstances, the used MODIS NDVI time series represent a good compromise between geometric and temporal resolution as well as temporal availability. At the same time, due to the temporal resolution of 16 days, it can also be assumed that the influence of any existing data gaps is smaller than with monthly data.

Methodically, the discussion should be focused on three points. At first, these are the interpolation methods applied for smoothing and gap-filling of the original time series before the metric calculation. In addition to the actual methodology of interpolation, the size or length of the gaps to be interpolated plays a decisive role. The quality of interpolation is very difficult to assess, because there is no insitu data available for validation. But the comparative analysis made in this study show that the selection of a method can certainly have an influence on the calculations of the phenological greening metrics. The impact of selected methods seems to be more important than missing data in the NDVI time series or the relatively coarse temporal resolution of the data. Depending on the interpolation overfitting must be avoided since this could lead to short-term impacts 
Table 4. Mann-Kendall trend test of LOS for different metric approaches and interpolation methods (2000-2015)

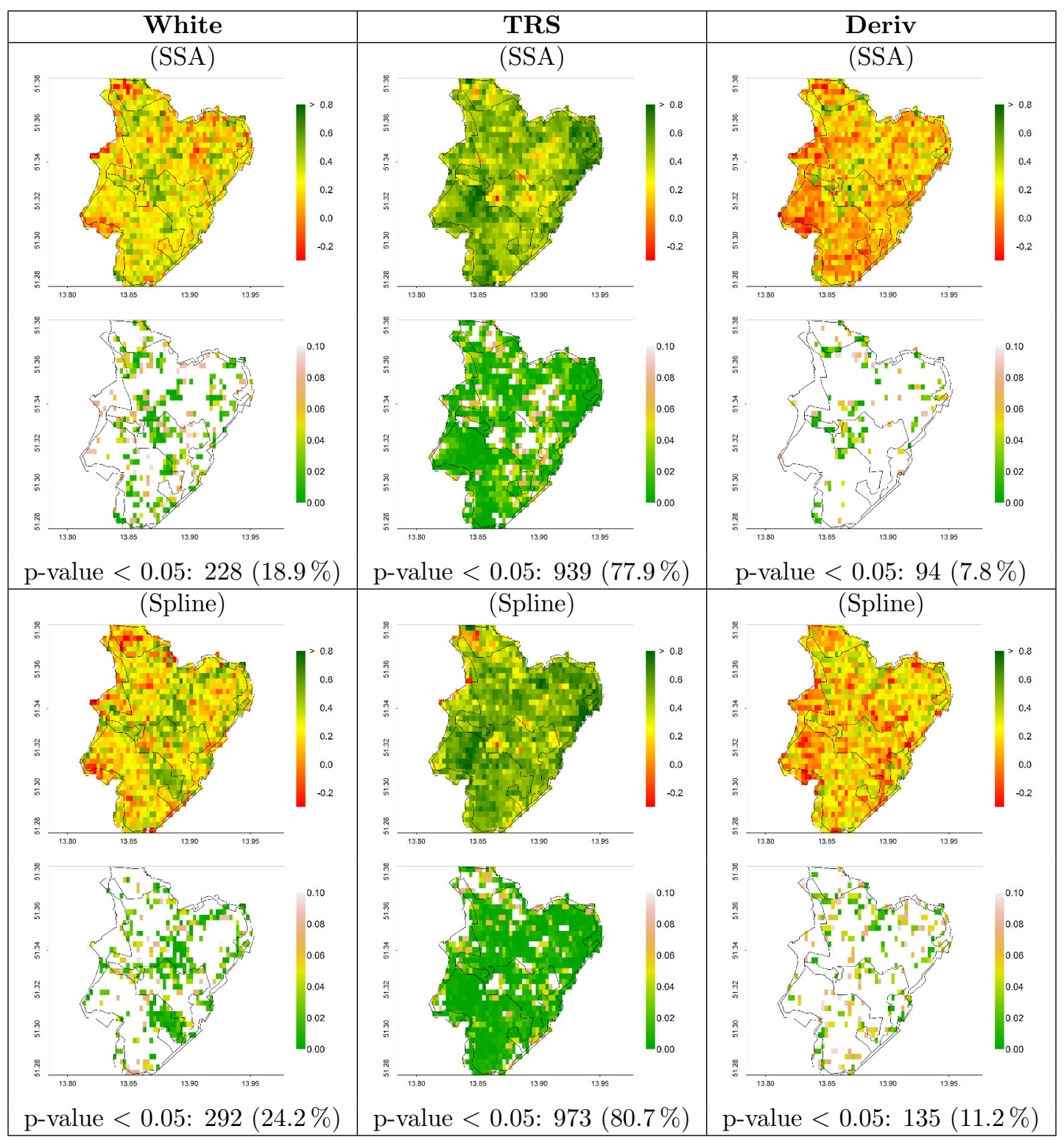

on the mathematical modeling of the phenological NDVI curve. Another option of the evaluation offer so-called Phenocams. Such digital time-lapse cameras offer the possibility of collecting high-resolution information about the vegetation status over a long period of time. ${ }^{44}$ They could then be used to determine the quality of the interpolations and their error budget at selected observation points in the study area.

Another point of the methodological discussion concerns the metrics and their derivation. As already described in chapter 2 , it is difficult to find stable points on the interpolated phenological curve. The present analyses have shown that different approaches for the determination of these points (key metrics) can lead to partly very different results. It has been shown that this not only affected the quantitative measure of vegetation dynamics, for example the number of days the start of season shift to an earlier date in the year, but that the results of other approaches conclude that there is a shift to a later day of the year. This ambivalence of the results show that the use of a single method should be avoided. Without further information, no valid decision 

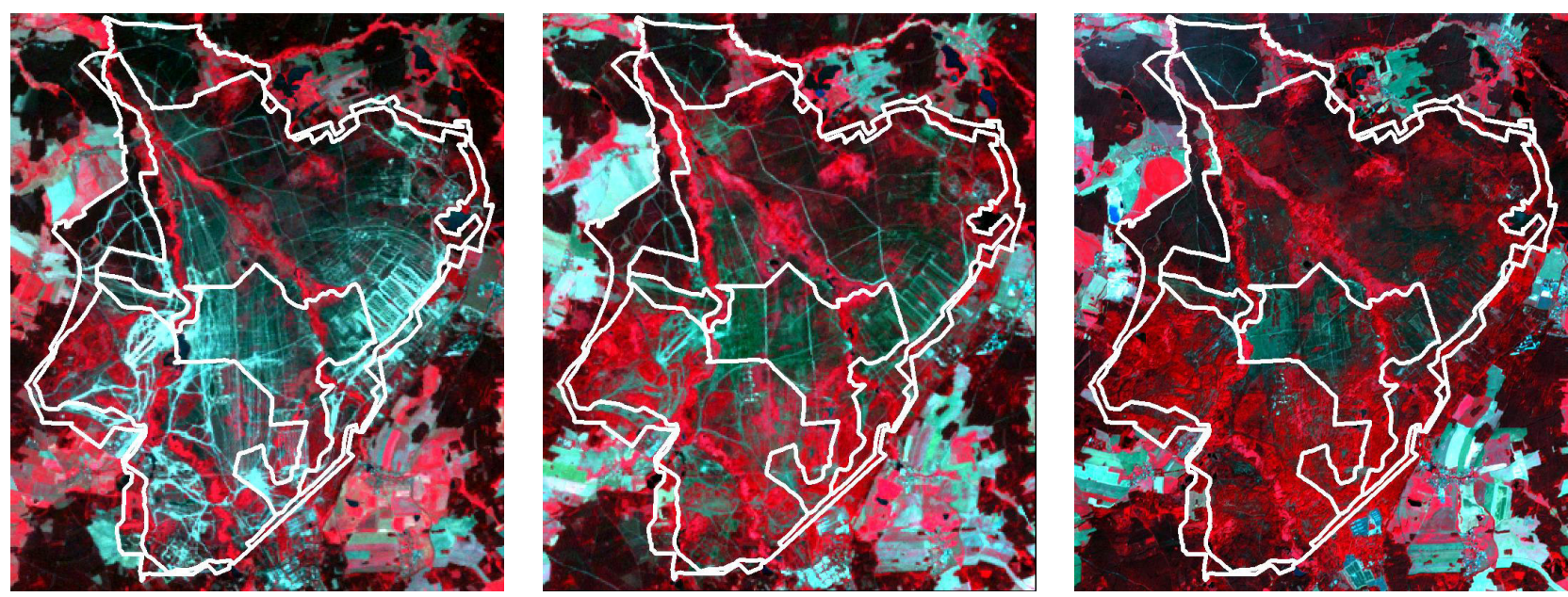

Figure 9. Left: 1992 (end of military use; Landsat 5); Middle: 2000 (start of MODIS time series; Landsat 7); Right: 2015 (end of MODIS time series, ASTER); Data Source: United States Geological Survey

can be made for the study area of the Königsbrücker Heide. Primarily such judgment refers to the independently calculated key metrics (SOS, EOS, LOS) and is based on these derived metrics as already presented in the chapter Methods \& Materials.

Therefore it must be stated that it is not possible to obtain sufficient information about the vegetation dynamics in the Königsbrücker Heide using the presented phenological and greenness metrics. This restriction does not apply to the fundamental development of vegetation in the study area. Wessollek and Karrasch (2016, 2017) were able to demonstrate dynamics in vegetation development. These dynamics mainly refer to a longterm trend, due to the transformation of the study area from military use to a protected area. ${ }^{19,20}$ This very hard change in land cover in some parts of the Königsbrücker Heide will also have had an impact on the phenological metrics treated in this study. In these areas, further investigations regarding the impact on the selected metric approach have to be examined. In order to be able to make valid statements about phenological development in the future, insitu observations will play a decisive role.

\section{REFERENCES}

[1] Dudley, N., ed., [Guidelines for Applying Protected Area Management Categories], Page Bros, Norwich, UK (2008).

[2] EUROPARC Deutschland, ed., [Richtlinien für die Anwendung der IUCN-Managementkategorien für Schutzgebiete - Deutsche Übersetzung (stellenweise gekürzt oder ergänzt)], IUCN (2010). Deutsche Übersetzung von: Dudley, N. (Editor) (2008) Guidelines for Applying Protected Area Management Categories.

[3] Nagendra, H., Lucas, R., Honrado, J. P., Jongman, R. H., Tarantino, C., Adamo, M., and Mairota, P., "Remote sensing for conservation monitoring: Assessing protected areas, habitat extent, habitat condition, species diversity, and threats," Ecological Indicators 33, 45 - 59 (2013). Biodiversity Monitoring.

[4] Lindenmayer, D. B. and Likens, G. E., "The science and application of ecological monitoring," Biological Conservation 143(6), 1317 - 1328 (2010).

[5] Willis, K. S., "Remote sensing change detection for ecological monitoring in united states protected areas," Biological Conservation 182, 233 - 242 (2015).

[6] Rouse, Jr., J. W., Haas, R. H., Schell, J. A., and Deering, D. W., "Monitoring Vegetation Systems in the Great Plains with Erts," NASA Special Publication 351, 309 (1974).

[7] Wessels, K., van den Bergh, F., and Scholes, R., "Limits to detectability of land degradation by trend analysis of vegetation index data," Remote Sensing of Environment 125, 10 - 22 (2012). 
[8] Lambert, J., Jacquin, A., Denux, J. P., and Chéret, V., "Comparison of two remote sensing time series analysis methods for monitoring forest decline," in [Analysis of Multi-temporal Remote Sensing Images (Multi-Temp), 2011 6th International Workshop on the], 93-96 (July 2011).

[9] Karlsen, S. R., Tolvanen, A., Kubin, E., Poikolainen, J., Hogda, K. A., Johansen, B., Danks, F. S., Aspholm, P., Wielgolaski, F. E., and Makarova, O., "Modis-ndvi-based mapping of the length of the growing season in northern fennoscandia," International Journal of Applied Earth Observation and Geoinformation 10(3), $253-266(2008)$.

[10] Jacquin, A., Sheeren, D., and Lacombe, J.-P., "Vegetation cover degradation assessment in madagascar savanna based on trend analysis of modis ndvi time series," International Journal of Applied Earth Observation and Geoinformation 12, Supplement 1, S3 - S10 (2010). Supplement Issue on "Remote Sensing for Africa - A Special Collection from the African Association for Remote Sensing of the Environment (AARSE)".

[11] Hutchinson, J., Jacquin, A., Hutchinson, S., and Verbesselt, J., "Monitoring vegetation change and dynamics on u.s. army training lands using satellite image time series analysis," Journal of Environmental Management 150, 355 - 366 (2015).

[12] Fensholt, R., Rasmussen, K., Nielsen, T. T., and Mbow, C., "Evaluation of earth observation based long term vegetation trends - intercomparing ndvi time series trend analysis consistency of sahel from AVHRR GIMMS, Terra MODIS and SPOT VGT data," Remote Sensing of Environment 113(9), 1886 - 1898 (2009).

[13] de Jong, R., de Bruin, S., de Wit, A., Schaepman, M. E., and Dent, D. L., "Analysis of monotonic greening and browning trends from global ndvi time-series," Remote Sensing of Environment 115(2), 692 - 702 (2011).

[14] de Beurs, K. M. and Henebry, G. M., "A statistical framework for the analysis of long image time series," International Journal of Remote Sensing 26(8), 1551-1573 (2005).

[15] Weiss, E., Marsh, S. E., and Pfirman, E. S., "Application of noaa-avhrr ndvi time-series data to assess changes in saudi arabia's rangelands," International Journal of Remote Sensing 22(6), 1005-1027 (2001).

[16] Pinzon, J. E. and Tucker, C. J., "A non-stationary 1981-2012 avhrr ndvi3g time series," Remote Sensing 6(8), 6929-6960 (2014).

[17] Forkel, M., Migliavacca, M., Thonicke, K., Reichstein, M., Schaphoff, S., Weber, U., and Carvalhais, N., "Codominant water control on global interannual variability and trends in land surface phenology and greenness," Global Change Biology 21(9), 3414-3435 (2015).

[18] Reppel, A. L., "Besucherkonzept für die königsbrücker heide - endbericht," tech. rep., Universität Paderborn (2003).

[19] Wessollek, C. and Karrasch, P., "Monitoring of vegetation dynamics on the former military training area königsbrücker heide using remote sensing time series," Proc.SPIE 10005, 10005 - 10005 - 12 (2016).

[20] Wessollek, C. and Karrasch, P., "Monitoring structural breaks in vegetation dynamics of the nature reserve königsbrückernigsbrücker heide," Proc.SPIE 10428, 10428 - 10428 - 17 (2017).

[21] Tateishi, R. and Ebata, M., "Analysis of phenological change patterns using 1982-2000 advanced very high resolution radiometer (avhrr) data," International Journal of Remote Sensing 25(12), 2287-2300 (2004).

[22] Tucker, C. J., Slayback, D. A., Pinzon, J. E., Los, S. O., Myneni, R. B., and Taylor, M. G., "Higher northern latitude normalized difference vegetation index and growing season trends from 1982 to 1999," International Journal of Biometeorology 45, 184-190 (Nov 2001).

[23] de Beurs, K. M. and Henebry, G. M., "Land surface phenology, climatic variation, and institutional change: Analyzing agricultural land cover change in kazakhstan," Remote Sensing of Environment 89(4), 497 - 509 (2004).

[24] Huete, A., Didan, K., Miura, T., Rodriguez, E., Gao, X., and Ferreira, L., "Overview of the radiometric and biophysical performance of the modis vegetation indices," Remote Sensing of Environment 83(1-2), 195 - 213 (2002). The Moderate Resolution Imaging Spectroradiometer (MODIS): a new generation of Land Surface Monitoring.

[25] Zhang, X., Friedl, M. A., Schaaf, C. B., Strahler, A. H., Hodges, J. C., Gao, F., Reed, B. C., and Huete, A., "Monitoring vegetation phenology using modis," Remote Sensing of Environment 84(3), 471 - 475 (2003). 
[26] Gao, F., Morisette, J. T., Wolfe, R. E., Ederer, G., Pedelty, J., Masuoka, E., Myneni, R., Tan, B., and Nightingale, J., "An algorithm to produce temporally and spatially continuous modis-lai time series," IEEE Geoscience and Remote Sensing Letters 5, 60-64 (Jan 2008).

[27] Verger, A., Baret, F., Weiss, M., Kandasamy, S., and Vermote, E., "The cacao method for smoothing, gap filling, and characterizing seasonal anomalies in satellite time series," IEEE Transactions on Geoscience and Remote Sensing 51, 1963-1972 (April 2013).

[28] Roerink, G. J., Menenti, M., and Verhoef, W., "Reconstructing cloudfree ndvi composites using fourier analysis of time series," International Journal of Remote Sensing 21(9), 1911-1917 (2000).

[29] Weiss, D. J., Atkinson, P. M., Bhatt, S., Mappin, B., Hay, S. I., and Gething, P. W., "An effective approach for gap-filling continental scale remotely sensed time-series," ISPRS Journal of Photogrammetry and Remote Sensing 98, 106 - 118 (2014).

[30] Kandasamy, S., Baret, F., Verger, A., Neveux, P., and Weiss, M., "A comparison of methods for smoothing and gap filling time series of remote sensing observations \&ndash; application to modis lai products," Biogeosciences 10(6), 4055-4071 (2013).

[31] Alavi, N., Warland, J. S., and Berg, A. A., "Filling gaps in evapotranspiration measurements for water budget studies: Evaluation of a kalman filtering approach," Agricultural and Forest Meteorology 141(1), 57 -66 (2006).

[32] Kalman, R. E., "A new approach to linear filtering and prediction problems," Journal of basic Engineering 82(1), 35-45 (1960).

[33] Eiurridge, P. and Wallis, K. F., "Seasonal adjustment and kalman filtering: Extension to periodic variances," Journal of Forecasting 9(2), 109-118 (1990).

[34] Golyandina, N., Viktorovich Nekrutkin, V., and Zhigljavsky, A., [Analysis of Time Series Structure: SSA and Related Techniques], vol. 90, Chapman \& Hall/CRC (01 2001).

[35] Mahecha, M. D., Fürst, L. M., Gobron, N., and Lange, H., "Identifying multiple spatiotemporal patterns: A refined view on terrestrial photosynthetic activity," Pattern Recognition Letters 31(14), 2309 - 2317 (2010).

[36] Hardle, W. and Steiger, W., "Algorithm as 296: Optimal median smoothing," Journal of the Royal Statistical Society. Series C (Applied Statistics) 44(2), 258-264 (1995).

[37] Dougherty, R. L., Edelman, A., and Hyman, J. M., "Nonnegativity-, monotonicity-, or convexity-preserving cubic and quintic hermite interpolation," Math. Comput.; (United States) 52:186 (4 1989).

[38] Fritsch, F. and Carlson, R., "Monotone piecewise cubic interpolation," SIAM Journal on Numerical Analysis 17(2), 238-246 (1980).

[39] Musial, J. P., Verstraete, M. M., and Gobron, N., "Technical note: Comparing the effectiveness of recent algorithms to fill and smooth incomplete and noisy time series," Atmospheric Chemistry and Physics 11(15), 7905-7923 (2011).

[40] Verbesselt, J., Hyndman, R., Zeileis, A., and Culvenor, D., "Phenological change detection while accounting for abrupt and gradual trends in satellite image time series," Remote Sensing of Environment 114(12), 2970 - 2980 (2010).

[41] Verbesselt, J., Zeileis, A., and Herold, M., "Near real-time disturbance detection using satellite image time series," Remote Sensing of Environment 123, 98 - 108 (2012).

[42] Clerici, N., Weissteiner, C. J., and Gerard, F., "Exploring the use of modis ndvi-based phenology indicators for classifying forest general habitat categories," Remote Sensing 4(6), 1781-1803 (2012).

[43] White, M. A., Thornton, P. E., and Running, S. W., "A continental phenology model for monitoring vegetation responses to interannual climatic variability," Global Biogeochemical Cycles 11(2), 217-234 (1997).

[44] Brown, T. B., Hultine, K. R., Steltzer, H., Denny, E. G., Denslow, M. W., Granados, J., Henderson, S., Moore, D., Nagai, S., SanClements, M., SÃjnchez-Azofeifa, A., Sonnentag, O., Tazik, D., and Richardson, A. D., "Using phenocams to monitor our changing earth: toward a global phenocam network," Frontiers in Ecology and the Environment 14(2), 84-93 (2016). 